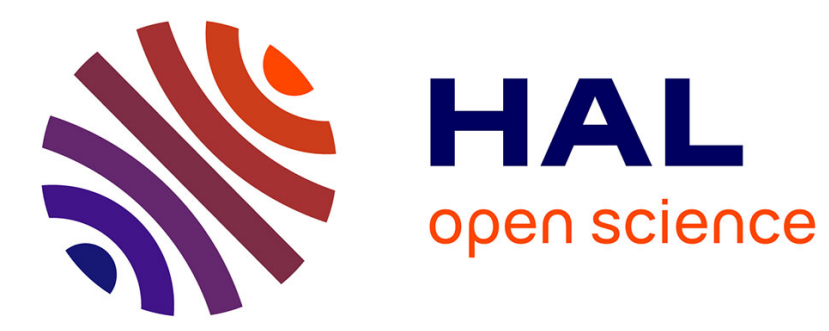

\title{
How should we determine normal echocardiographic right ventricle function reference values in pediatrics?
}

Charlène Bredy, Camille Soulatges, Sophie Guillaumont, Marie Vincenti, Gregoire de La Villeon, Thibault Mura, Pascal Amedro

\section{- To cite this version:}

Charlène Bredy, Camille Soulatges, Sophie Guillaumont, Marie Vincenti, Gregoire de La Villeon, et al.. How should we determine normal echocardiographic right ventricle function reference values in pediatrics?. International Journal of Cardiovascular Imaging, 2018, 10.1007/s10554-018-1462-6 . hal-01884828

\section{HAL Id: hal-01884828 \\ https://hal.umontpellier.fr/hal-01884828}

Submitted on 3 Jan 2020

HAL is a multi-disciplinary open access archive for the deposit and dissemination of scientific research documents, whether they are published or not. The documents may come from teaching and research institutions in France or abroad, or from public or private research centers.
L'archive ouverte pluridisciplinaire HAL, est destinée au dépôt et à la diffusion de documents scientifiques de niveau recherche, publiés ou non, émanant des établissements d'enseignement et de recherche français ou étrangers, des laboratoires publics ou privés. 


\title{
How should we determine normal echocardiographic right ventricle function reference values in pediatrics?
}

\author{
Charlene Bredy $^{1}$ - Camille Soulatges ${ }^{1}$. Sophie Guillaumont ${ }^{1,2} \cdot$ Marie Vincenti $^{1,5} \cdot$ Gregoire De La Villeon $^{1,2}$. \\ Thibault Mura ${ }^{3,4} \cdot$ Pascal Amedro ${ }^{1,5}$ (D)
}

\begin{abstract}
Several models have been used to establish pediatric Z-scores for echocardiographic right ventricle (RV) variables. This study aimed to determine the most appropriate mathematical model for RV function reference values in pediatrics. Prospective cross-sectional study among 314 healthy children ages 2 days to 18 years (46\% female, 88 infants, 26 neonates, 226 children). RV parameters ( $\mathrm{S}^{\prime}, \mathrm{E}^{\prime}, \mathrm{A}^{\prime}$ waves, TEI index, TAPSE) were modelized with four explanatory variables: age, height, weight and body surface area. Four mathematical models were applied: a linear model, a polynomial model of degree 2, a linear regression model by spline with free knot, and a polynomial regression model of degree 2 by spline with a free knot. The choice of the best method used the adjusted coefficient of determination $\left(\mathrm{aR}^{2}\right)$. The modelization of $\mathrm{RV}$ variables did not follow a linear model. A single explanatory variable could not determine all Z-scores, as specific and independent variables were required for each parameter. The quadratic spline model best adjusted the modelization of RV variables. The $S^{\prime}$ wave was best modelized by the spline model with the weight (knot at $6.86 \mathrm{~kg}$ ). The $\mathrm{E}^{\prime}$ wave was best modelized by the spline model with the age (knot at 0.29 years). The $\mathrm{A}^{\prime}$ wave was best modelized by the model with the height $(\mathrm{knot}$ at $81 \mathrm{~cm})$. The TAPSE was best modelized by the spline model with the weight (knot at $9.04 \mathrm{~kg}$ ). The spline regression models best applies to echocardiographic RV reference values in pediatrics.
\end{abstract}

Keywords Heart ventricles $\cdot$ Echocardiography $\cdot$ Child $\cdot$ Pediatrics $\cdot$ Diagnosis imaging $\cdot$ Mathematics

\section{Introduction}

In the context of medical and surgical advances in pediatric cardiology, increased attention has been recently given to heart diseases involving the right ventricle (RV) [1]. The care of these young patients includes complex surgical

Pascal Amedro

p-amedro@chu-montpellier.fr

Pediatric and Congenital Cardiology Department, M3C Regional Reference Centre, University Hospital, Montpellier, France

2 Pediatric Cardiology and Rehabilitation Unit, St-Pierre Institute, Palavas-les-Flots, France

3 Clinical Research and Epidemiology Unit, University Hospital, Montpellier, France

4 INSERM-CIC 1411, Clinical Investigation Centre, University Hospital, Montpellier, France

5 PHYMEDEXP, CNRS, INSERM, University of Montpellier, Montpellier, France reconstruction of the right outflow tract, balloon or stenting in the pulmonary arteries and advance pharmaceutical therapies for pulmonary arterial hypertension. As a result, echocardiographic assessment of RV function has become essential in pediatric cardiology. However, this evaluation is based on the existence of reliable normal values for each $\mathrm{RV}$ index, taking into account the growth from the neonate to the teenager.

Several mathematic models have been used to establish pediatric Z-scores for the main RV function variables: tricuspid annular plane systolic excursion (TAPSE) [2-4], pulsed wave tissue Doppler imaging (TDI) of the tricuspid annulus [5, 6], and index of myocardial performance (TEI index) [6-10]. Most authors have used linear regression models. However, the relevance of a linear model might raise questions when considering the non-linear child's growth between birth and adulthood, along with the significant physiological change defining RV hemodynamic. Wang et al. recently stated that a cubic polynomial model best described the RV norms in 515 children [11]. Other 
more flexible mathematical models such as spline functions have been applied to medicine in oxidation curves or normal values for spirometry, but to our knowledge, not in echocardiography [12-14].

The aim of our study was to determine whether a nonlinear mathematical model could improve the quality of $\mathrm{Z}$-scores for $\mathrm{RV}$ function reference values in normal children.

\section{Method}

\section{Study design and patients}

This prospective cross-sectional study was carried out over 6 months in a tertiary care pediatric cardiology department. We screened children aged 0-18 years referred to the outpatient pediatric cardiology consultation for murmur, chest pain, palpitations or sport certificate. Only those with normal physical examination, electrocardiogram and echocardiogram were eligible for the study. Children with any chronic disease or under any treatment were not included. This study was conducted in compliance with the Good Clinical Practices protocol and Declaration of Helsinki principles, after approval of the CCTIRS Ethics Committee (national advisory committee for data processing in health research). Informed consent was obtained from all parents or legal guardians.

\section{Echocardiographic measurements}

Echocardiographic examinations were performed using an IE-33 ultrasound (Philips Healthcare). The study of RV function can be evaluated using several imaging and functional modalities reflecting RV systolic and diastolic function. The most commonly used echocardiographic indices of RV systolic function are TAPSE, which reflect the extent of contraction, myocardial velocity indices such as the tricuspid annular plane maximal systolic velocity and hemodynamic indices such as interval indices (TEI index), which reflect both systolic and diastolic parameters.

Doppler echocardiography parameters were collected according to international guidelines $[15,16]$. Three consecutive cycles were averaged for every parameter. Following RV function variables were collected in the fourchamber view: TDI $E^{\prime}, \mathrm{A}^{\prime}$ and $\mathrm{S}$ waves, TDI TEI Index of myocardial performance and TAPSE $[2,5,17]$. The myocardial systolic and diastolic velocities were obtained by placing a TDI sample volume at the lateral tricuspid annulus. We calculated the TEI index derived from TDI. We divided the isovolumic time [assessed as the time between tricuspid valve closure (end of $\mathrm{A}^{\prime}$ ) and opening (start of $\mathrm{E}^{\prime}$ ) minus the ejection time (duration of $\mathrm{S}^{\prime}$ )] by the ejection time. TAPSE was measured using M-mode from the tricuspid lateral annulus. Two left ventricle data were informed to control the normality of the population: the left ventricle ejection fraction (LVEF), measured with the Teichholz formula, and the wall stress (WS). LVEF using the Teichholz formula was obtained in a long axis view, left ventricular measurements were made with the M-mode beam positioned just beyond the mitral leaflet tips in diastole, perpendicular to the long axis of the left ventricle. Both ventricular diameters (systolic and diastolic) were measured from the leading edge to leading edge of each interface, and LVEF by Teichholz is then calculated using the ultrasound software. The WS assessed the tension within the wall of the left ventricle [18]. It was determined by the pressure in the ventricle using cuff blood pressure at the time of echocardiography, the internal radius of the ventricle by $\mathrm{M}$-mode, and the thickness of the wall. The blood pressure was measured when the child was calm, using a manual sphygmomanometer with adapted pediatric cuffs.

\section{Statistical analysis}

The characteristics of the children included in the study were described with proportions for categorical variables and with means and standard deviation (SD) values for continuous variables. The comparison parameters between ultrasound equipment were performed using student t-test. In order to identify the best model for the Z-Score construction, each RV parameters $\left(S^{\prime}, E^{\prime}, A^{\prime}\right.$ waves, TEI index, TAPSE) was modelized with four explanatory variables: age, height, weight and body surface area. Four different mathematical models were successively applied: (1) a linear model, (2) a polynomial model of degree 2, (3) a linear regression model by spline with free knot (a single knot whose location has been identified using the method presented by Molinari et al. [13]), and (4) a polynomial regression model of degree 2 by spline with a free knot (modelization with a single knot). The use of a spline regression model, allows modeling a variable by a line or a curve presenting a sudden change of slope at a point named "knot". The choice of the best explanatory variable and the best modelization method was made on the basis of the adjusted coefficient of determination $\left(\mathrm{aR}^{2}\right)$, which takes into account the number of explanatory terms in a model relative to the sample size, and avoids the choice of an over-fitted model. The results of the chosen model were then plotted by estimating the evolution of each RV parameter's mean with its confidence interval at $95 \%$ and prediction intervals at $1 \mathrm{SD}$ and $2 \mathrm{SD}$ (Z-scores).

Statistical significance was set at 0.05 and analyses were performed using SAS version 9 (SAS Institute, Cary, NC). 
Table 1 Population

\begin{tabular}{lllll}
\hline & Total & Female & Male & p Value \\
\hline Patients $(\mathrm{N}, \%)$ & $314(100 \%)$ & $144(46 \%)$ & $170(54 \%)$ & \\
Age (years \pm SD) & $6.1 \pm 5.1$ & $5.9 \pm 5$ & $6.3 \pm 5.25$ & 0.76 \\
Weight $(\mathrm{kg} \pm \mathrm{SD})$ & $23.1 \pm 17.2$ & $23 \pm 17.5$ & $23.2 \pm 16.9$ & 0.88 \\
Height $(\mathrm{cm} \pm \mathrm{SD})$ & $108.2 \pm 38.9$ & $107.7 \pm 37.9$ & $108 \pm 39.8$ & 0.87 \\
BSA $\left(\mathrm{m}^{2} \pm \mathrm{SD}\right)$ & $0.81 \pm 0.45$ & $0.81 \pm 0.44$ & $0.81 \pm 0.44$ & 0.88 \\
LVEF $(\% \pm \mathrm{SD})$ & $69.9 \pm 6.43$ & $70.2 \pm 7$ & $69.6 \pm 5.8$ & 0.41 \\
WS $\left(\mathrm{g} / \mathrm{cm}^{2} \pm \mathrm{SD}\right)$ & $49.1 \pm 21.2$ & $48.9 \pm 21.2$ & $49.1 \pm 21.2$ & 0.41 \\
\hline
\end{tabular}

$S D$ standard deviation, $B S A$ body surface area, $L V E F$ left ventricle ejection fraction, WS wall stress

Table 2 RV variables

\begin{tabular}{lcccl}
\hline & N & Mean \pm SD & Range & $\begin{array}{l}\text { Missing } \\
\text { data }(\%)\end{array}$ \\
\hline TAPSE $(\mathrm{mm})$ & 292 & $18.7 \pm 4.9$ & $6.6-33$ & 7 \\
$\mathrm{~S}^{\prime}(\mathrm{cm} / \mathrm{s})$ & 299 & $12 \pm 2.2$ & $6-21.1$ & 5 \\
$\mathrm{E}^{\prime}(\mathrm{cm} / \mathrm{s})$ & 298 & $13.7 \pm 3.8$ & $3.45-26.6$ & 5.1 \\
$\mathrm{~A}^{\prime}(\mathrm{cm} / \mathrm{s})$ & 286 & $10.1 \pm 3.7$ & $3.9-38$ & 9 \\
TEI index & 275 & $0.41 \pm 0.11$ & $0.08-0.95$ & 12.5 \\
\hline
\end{tabular}

\section{Results}

\section{Population}

Within the 24-month study period, 6407 children were referred to the pediatric cardiology outpatient consultation. We included 314 normal children aged 2 days to 18 years (46\% female, 88 infants under 1 year old, 26 neonates, 226 children). One family refused to participate. No demographic differences were observed between male and female (Table 1).

\section{RV variables}

The five RV variables (mean values and ranges) measured in the present study were presented in Table 2 . The modelization of these echocardiographic RV variables over all ages did not follow a linear model, according to all four explanatory variables (age, height, weight and body surface area), with the lowest adjusted coefficients of determination $\left(\mathrm{aR}^{2}\right)$ in those four variables (Table 3 ). The quadratic spline model best adjusted the modelization of all RV variables, but with little difference with the linear spline model. No model accurately explained the TEI index in any of the four explanatory variables. The $\mathrm{S}^{\prime}$ wave was best modelized by the quadratic spline model with the weight (Fig. 1a). The knot at $6.86 \mathrm{~kg}$ corresponded to the curves' break (Fig. 1b). The $\mathrm{E}^{\prime}$ wave was best modelized by the quadratic spline model with the
Table 3 Modelization of RV variables

\begin{tabular}{|c|c|c|c|c|c|c|c|c|c|c|c|}
\hline & \multirow[t]{2}{*}{ RV variable } & \multicolumn{2}{|l|}{$\mathrm{S}^{\prime}$} & \multicolumn{2}{|l|}{$\mathrm{E}^{\prime}$} & \multicolumn{2}{|l|}{$\mathrm{A}^{\prime}$} & \multicolumn{2}{|c|}{ TEI index } & \multicolumn{2}{|c|}{ TAPSE } \\
\hline & & $\overline{\text { Knot }}$ & $\mathrm{aR}^{2^{*}}$ & $\overline{\text { Knot }}$ & $\mathrm{aR}^{2^{*}}$ & $\overline{\text { Knot }}$ & $\mathrm{aR}^{2^{*}}$ & $\overline{\text { Knot }}$ & $\overline{\mathrm{aR}^{2}}$ & $\overline{\text { Knot }}$ & $\mathrm{aR}^{2 *}$ \\
\hline \multirow{5}{*}{ Age (years) } & Mathematical model & & & & & & & & & & \\
\hline & Linear & & 0.12 & & 0.10 & & 0.13 & & 0.01 & & 0.55 \\
\hline & Quadratic polynomial & & 0.13 & & 0.12 & & 0.14 & & 0.01 & & 0.60 \\
\hline & Linear spline & 0.11 & 0.25 & 0.29 & 0.25 & 8.27 & 0.14 & 3.79 & 0.01 & 0.37 & 0.68 \\
\hline & Quadratic spline & 0.28 & 0.24 & 0.29 & 0.27 & 8.27 & 0.15 & 7.7 & 0.00 & 0.46 & 0.69 \\
\hline \multirow[t]{4}{*}{ Height (cm) } & Linear & & 0.15 & & 0.14 & & 0.12 & & 0.01 & & 0.64 \\
\hline & Quadratic polynomial & & 0.18 & & 0.18 & & 0.12 & & 0.01 & & 0.67 \\
\hline & Linear spline & 58 & 0.23 & 56 & 0.26 & 57 & 0.15 & 115 & 0.01 & 68 & 0.69 \\
\hline & Quadratic spline & 64 & 0.22 & 62 & 0.25 & 81 & 0.16 & 154 & 0.00 & 80 & 0.69 \\
\hline \multirow[t]{4}{*}{ Weight $(\mathrm{kg})$} & Linear & & 0.11 & & 0.10 & & 0.09 & & 0.01 & & 0.49 \\
\hline & Quadratic polynomial & & 0.18 & & 0.15 & & 0.11 & & 0.01 & & 0.64 \\
\hline & Linear spline & 5.84 & 0.24 & 4.54 & 0.27 & 4.42 & 0.11 & 6.39 & 0.01 & 9.16 & 0.66 \\
\hline & Quadratic spline & 6.86 & 0.25 & 6.18 & 0.27 & 5.94 & 0.14 & 6.39 & 0.02 & 9.04 & 0.70 \\
\hline \multirow[t]{4}{*}{ BSA $\left(\mathrm{kg} / \mathrm{m}^{2}\right)$} & Linear & & 0.14 & & 0.13 & & 0.10 & & 0.01 & & 0.57 \\
\hline & Quadratic polynomial & & 0.19 & & 0.17 & & 0.11 & & 0.01 & & 0.67 \\
\hline & Linear spline & 0.31 & 0.24 & 0.29 & 0.26 & 0.27 & 0.13 & 0.77 & 0.01 & 0.42 & 0.68 \\
\hline & Quadratic spline & 0.38 & 0.24 & 0.35 & 0.26 & 0.34 & 0.15 & 0.78 & 0.00 & 0.41 & 0.69 \\
\hline
\end{tabular}

$B S A$ body surface area, $R V$ right ventricle, $a R^{2}$ adjusted coefficient of determination

*All $\mathrm{aR}^{2}$ (except for TEI index) are significantly different from 0 ( $\mathrm{p}$ value $<0.0001$ ) 




Fig. 1 a Modelization of $\mathrm{S}^{\prime}$ wave with quadratic spline model (all weight ranges). The green bands correspond to the $95 \%$ confidence interval, the black dotted bands correspond to the 1SD prediction interval, and the blue dotted bands correspond to the 1SD predic-

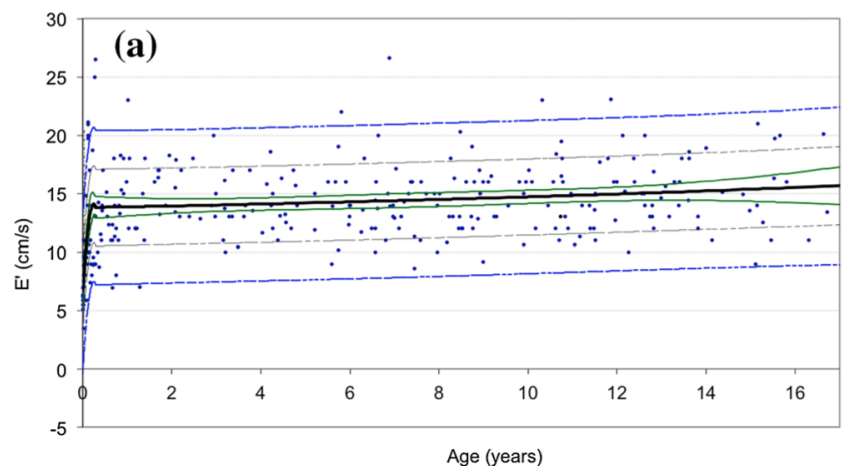

Fig. 2 a Modelization of $\mathrm{E}^{\prime}$ wave with quadratic spline model (all ages). The green bands correspond to the $95 \%$ confidence interval, the black dotted bands correspond to the 1SD prediction interval, and the blue dotted bands correspond to the 1SD prediction interval. $\mathbf{b}$

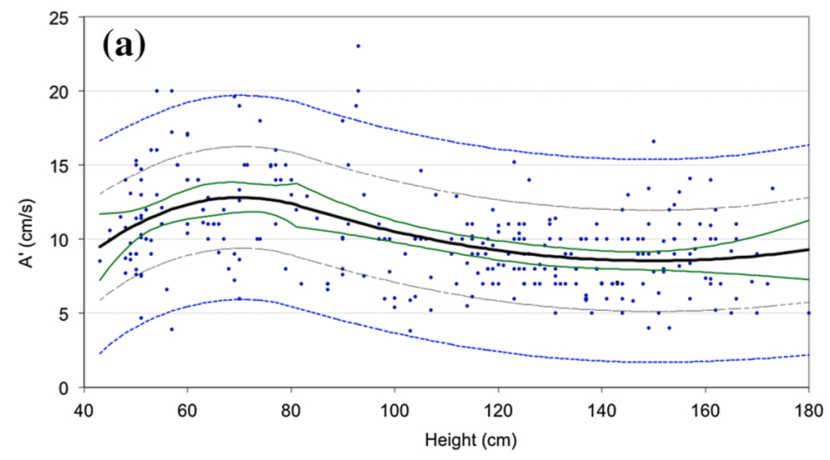

Fig. 3 a Modelization of $\mathrm{A}^{\prime}$ wave with quadratic spline model (all height ranges). The green bands correspond to the $95 \%$ confidence interval, the black dotted bands correspond to the 1SD prediction interval, and the blue dotted bands correspond to the 1SD prediction

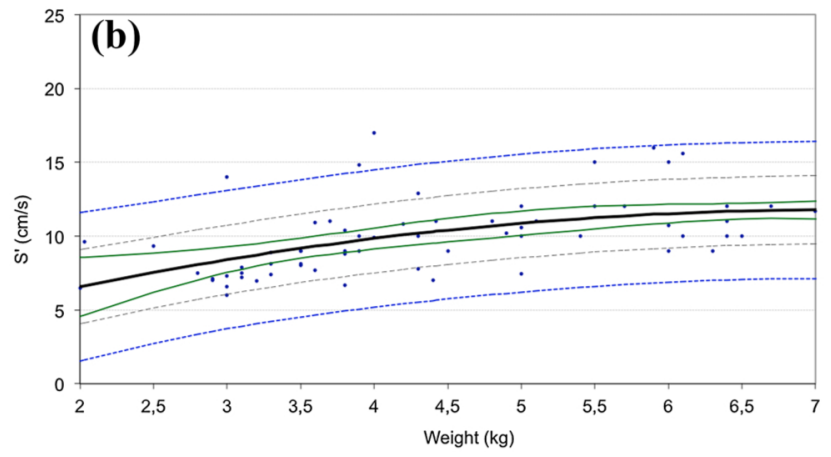

tion interval. b Modelization of $\mathbf{S}^{\prime}$ wave with quadratic spline model $(2-7 \mathrm{~kg})$. The green bands correspond to the $95 \%$ confidence interval, the black dotted bands correspond to the 1SD prediction interval, and the blue dotted bands correspond to the 1SD prediction interval

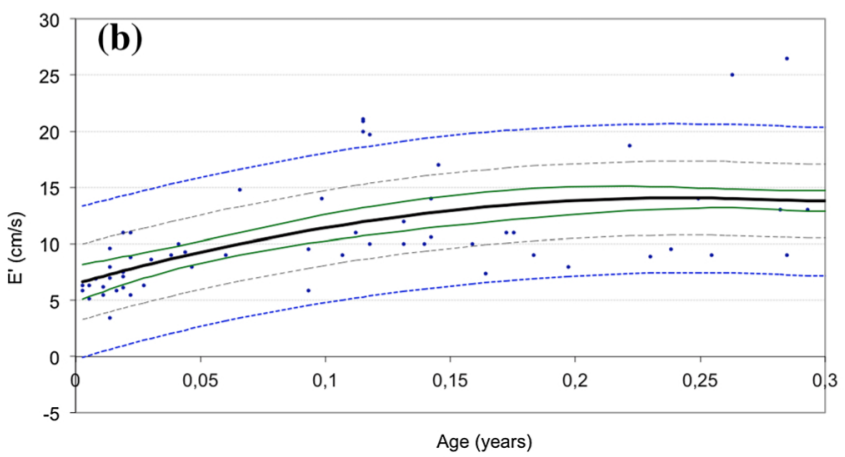

Modelization of $\mathrm{E}^{\prime}$ wave with quadratic spline model ( $0-0.3$ years). The green bands correspond to the $95 \%$ confidence interval, the black dotted bands correspond to the 1SD prediction interval, and the blue dotted bands correspond to the 1SD prediction interval



interval. b Modelization of $\mathrm{A}^{\prime}$ wave with quadratic spline model (40$80 \mathrm{~cm})$. The green bands correspond to the $95 \%$ confidence interval, the black dotted bands correspond to the 1SD prediction interval, and the blue dotted bands correspond to the 1SD prediction interval 


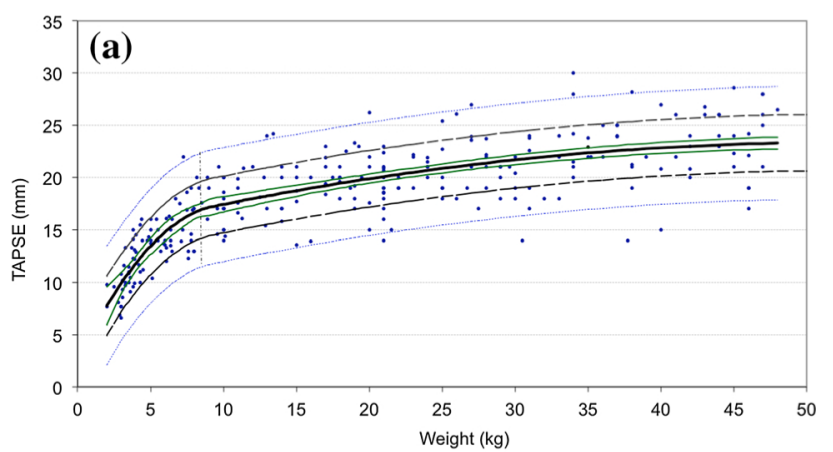

Fig. 4 a Modelization of TAPSE with quadratic spline model (all weight ranges). The green bands correspond to the $95 \%$ confidence interval, the black dotted bands correspond to the 1SD prediction interval, and the blue dotted bands correspond to the 1SD predic-

age (Fig. 2a). The knot at 0.29 years corresponded to the curve's break (Fig. 2b). The A' wave was best modelized by the quadratic model with the height (Fig. 3a). The knot at $81 \mathrm{~cm}$ corresponded to the break of the curve (Fig. 3b). The TAPSE was best modelized by the quadratic spline model with the weight (Fig. 4a). The knot at $9.04 \mathrm{~kg}$ corresponded to the curve's break (Fig. 4b).

\section{Discussion}

This study of a large cohort of 314 children presented four mathematical models to define RV Z-scores in normal children. Among these models, the use of spline regression models appeared to improve the quality of the mathematical modeling for most echocardiographic RV parameters. The choice of a single-node spline method was made on the basis of the graphical representation of our data, which clearly showed a single break in the curve for several parameters $\left(\mathrm{S}^{\prime}\right.$, $\mathrm{E}^{\prime}$ and TAPSE). Moreover, we focused on the curve breaks values, which could be clinically relevant. The single-node spline method that we used, developed by Molinari et al., provided a way to statistically determine the best value of this breakpoint $[12,13]$. Modeling using splines with two or more nodes (set a priori and not by the model) did not provide this type of information.

Despite recent advances, echocardiographic RV parameters nomograms are limited in the pediatric population. Indeed, there are several methodological issues including the lack of standardization, the different types of body size measurements used for normalization, and the various ways to express normalized data $[19,20]$. Moreover, if reference values seem to be reproducible in older children, they vary significantly in neonates and infants [21].

By evaluating the main parameters used to evaluate RV function in pediatric population, our data showed that linear

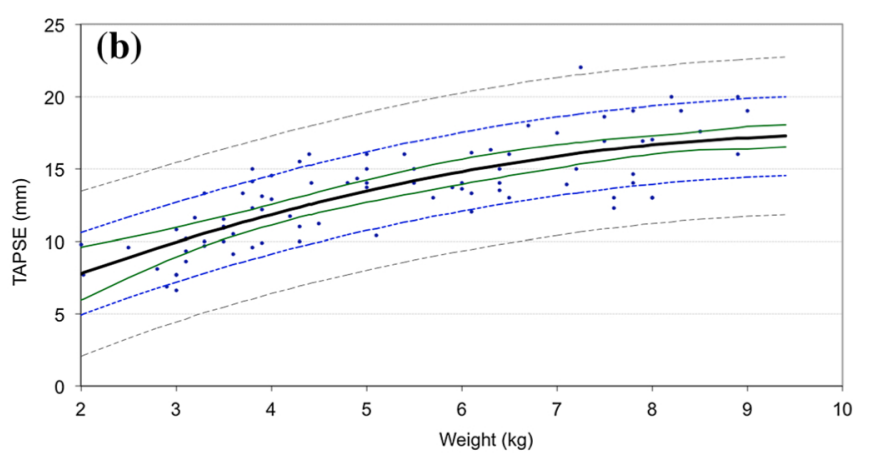

tion interval. b Modelization of TAPSE with quadratic spline model $(2-10 \mathrm{~kg})$. The green bands correspond to the $95 \%$ confidence interval, the black dotted bands correspond to the 1SD prediction interval, and the blue dotted bands correspond to the 1SD prediction interval

or quadratic polynomial models were not appropriate. Our results suggested that spline regression models with one knot were better mathematical models to modelize RV parameters. Our data also supported that RV parameters evolution was not linear during childhood but presented several curves' breaks. Moreover, these curves' breaks did not relate to a single anthropometric variable. As opposed to other authors who commonly associated echocardiographic measurement to only one variable (body surface area, weight or height) to calculate Z-scores, we pointed out that specific and independent variables were required for each parameter. Indeed, the best independent variable used to predict the mean value of the $S$ wave and the TAPSE was the weight, whereas it was the age for the $\mathrm{E}$ wave and the height for the A wave. These findings show that all anthropometric variables should be considered in the pediatric population. Nevertheless, no variable or mathematical model was related to the TEI index.

Using linear regression model based on a single variable to determine Z-scores and norms in the pediatric population might lead to major and systematic biases for certain age groups, especially neonates and infants. This might have pejorative consequences if used in acquired or congenital heart diseases.

New mathematical models to determine norms in children have been also studied by Wang and al. These authors provided reference values for RV echocardiographic parameters using a cubic polynomial relationship with BSA and for coronary artery using a cubic regression in a large cohort of Chinese children [22, 23]. Our study highlighted that this type of model was actually more pertinent than a linear regression for norm construction. However, the adequacy of modeling can still be improved by using spline models.

Spline regression models have recently generated some interest in adult cardiology and could probably apply to various situations in the field of pediatric cardiology. Indeed, 
in a study among adults with asymptomatic primary mitral regurgitation and preserved ejection fraction, Mentias et al. showed with a quadratic spline analysis, that the risk of death progressively increased as resting left ventricle global longitudinal strain worsened [24]. Similarly, Rabkin et al. measured the association between age and QT interval and found that the cubic spline had significant increases in adjusted- $R^{2}$ compared to linear model in male adults [25]. Recently, Zhou et al. used a spline-automated method to identify the best-quality coronary arterial segment from multiple-phase coronary CT angiography acquisitions [26].

\section{Study limitations}

With a sample size of 312 children, $\mathrm{aR}^{2}$ for $\mathrm{S}^{\prime}, \mathrm{E}^{\prime}, \mathrm{A}^{\prime}$ and TEI index were below 0.3 . Missing data represented 5-12\% of variables collected but this range is relatively small for a pediatric study as patient's cooperation might be limited. Even if there is no "magic number", generally an $\mathrm{aR}^{2}>0.6$ is considered as statistically reliable and only $\mathrm{aR}^{2}$ for TAPSE was $>0.6$ in our results [27].

The sample size required for pediatric nomograms has been indicated in previous publications and should ideally be at least of 600 subjects $[28,29]$. However, this study did not intend to define new Z-scores, but mostly aimed to criticize linear models regularly used in cardiovascular imaging studies and define a more accurate mathematical model to use in pediatric cardiology.

\section{Conclusions}

Because of several curve breaks during childhood, linear model might not be relevant to define normal echocardiographic values in infants and children. Our data suggested that the spline regression models represented more appropriate mathematical models to assess right ventricular function than linear or quadratic polynomial ones, and might be used to determine normal values in pediatrics. The spline models should probably be tested in future pediatric cardiovascular imaging studies.

Funding This study was funded by the pediatric and congenital cardiology clinical research association in Montpellier University Hospital funded this study.

\section{Compliance with ethical standards}

Conflict of interest Authors declare that they have no conflict of interest.

Ethical approval All procedures performed in studies involving human participants were in accordance with the ethical standards of the institutional and/or national research committee and with the 1964 Helsinki declaration and its later amendments or comparable ethical standards.
Informed consent Informed consent was obtained from all individual participants included in the study.

\section{References}

1. Khairy P, Ionescu-Ittu R, Mackie AS, Abrahamowicz M, Pilote L, Marelli AJ (2010) Changing mortality in congenital heart disease. J Am Coll Cardiol 56(14):1149-1157. https://doi.org/10.1016/j. jacc.2010.03.085

2. Koestenberger M, Ravekes W, Everett AD, Stueger HP, Heinzl B, Gamillscheg A, Cvirn G, Boysen A, Fandl A, Nagel B (2009) Right ventricular function in infants, children and adolescents: reference values of the tricuspid annular plane systolic excursion (TAPSE) in 640 healthy patients and calculation of $\mathrm{z}$ score values. J Am Soc Echocardiogr 22(6):715-719. https://doi.org/10.1016/j. echo.2009.03.026

3. Nunez-Gil IJ, Rubio MD, Carton AJ, Lopez-Romero P, Deiros L, Garcia-Guereta L, Labrandero C, Gutierrez-Larraya F (2011) Determination of normalized values of the tricuspid annular plane systolic excursion (TAPSE) in 405 Spanish children and adolescents. Rev Esp Cardiol 64(8):674-680. https://doi.org/10.1016/j. recesp.2011.04.006

4. Uysal F, Bostan OM, Cil E (2016) Determination of reference values for tricuspid annular plane systolic excursion in healthy Turkish children. Anatol J Cardiol 16(5):354-359. https://doi. org/10.5152/akd.2015.6227

5. Roberson DA, Cui W, Chen Z, Madronero LF, Cuneo BF (2007) Annular and septal Doppler tissue imaging in children: normal $\mathrm{z}$-score tables and effects of age, heart rate, and body surface area. J Am Soc Echocardiogr 20(11):1276-1284. https://doi. org/10.1016/j.echo.2007.02.023

6. Eidem BW, McMahon CJ, Cohen RR, Wu J, Finkelshteyn I, Kovalchin JP, Ayres NA, Bezold LI, O’Brian Smith E, Pignatelli RH (2004) Impact of cardiac growth on Doppler tissue imaging velocities: a study in healthy children. J Am Soc Echocardiogr 17(3):212-221. https://doi.org/10.1016/j.echo.2003.12.005

7. Roberson DA, Cui W (2007) Right ventricular Tei index in children: effect of method, age, body surface area, and heart rate. $J$ Am Soc Echocardiogr 20(6):764-770. https://doi.org/10.1016/j. echo.2006.11.002

8. Eidem BW, Tei C, O’Leary PW, Cetta F, Seward JB (1998) Nongeometric quantitative assessment of right and left ventricular function: myocardial performance index in normal children and patients with Ebstein anomaly. J Am Soc Echocardiogr 11(9):849-856

9. Harada K, Tamura M, Toyono M, Yasuoka K (2002) Comparison of the right ventricular Tei index by tissue Doppler imaging to that obtained by pulsed Doppler in children without heart disease. Am J Cardiol 90(5):566-569

10. Ishii M, Eto G, Tei C, Tsutsumi T, Hashino K, Sugahara Y, Himeno W, Muta H, Furui J, Akagi T, Fukiyama R, Toyoda O, Kato H (2000) Quantitation of the global right ventricular function in children with normal heart and congenital heart disease: a right ventricular myocardial performance index. Pediatr Cardiol 21(5):416-421

11. Wang SS, Zhang YQ, Chen SB, Huang GY, Zhang HY, Zhang ZF, Wu LP, Hong WJ, Shen R, Liu YQ, Zhu JX (2017) Regression equations for calculation of $\mathrm{z}$ scores for echocardiographic measurements of right heart structures in healthy Han Chinese children. J Clin Ultrasound. https://doi.org/10.1002/jcu.22436

12. Molinari N, Daures JP, Durand JF (2001) Regression splines for threshold selection in survival data analysis. Stat Med 20(2):237-247 
13. Molinari N, Morena M, Cristol JP, Daure JP (2002) Free knot splines for biochemical data. Comput Methods Programs Biomed 67(3):163-167

14. Kainu A, Timonen K (2016) Polynomial estimation of the smoothing splines for the new Finnish reference values for spirometry. Scand J Clin Lab Invest 76(4):313-318. https://doi. org/10.3109/00365513.2016.1158417

15. Lopez L, Colan SD, Frommelt PC, Ensing GJ, Kendall K, Younoszai AK, Lai WW, Geva T (2010) Recommendations for quantification methods during the performance of a pediatric echocardiogram: a report from the Pediatric Measurements Writing Group of the American Society of Echocardiography Pediatric and Congenital Heart Disease Council. J Am Soc Echocardiogr 23(5):465-495. https://doi.org/10.1016/j.echo.2010.03.019 (quiz 576-467)

16. Rudski LG, Lai WW, Afilalo J, Hua L, Handschumacher MD, Chandrasekaran K, Solomon SD, Louie EK, Schiller NB (2010) Guidelines for the echocardiographic assessment of the right heart in adults: a report from the American Society of Echocardiography endorsed by the European Association of Echocardiography, a registered branch of the European Society of Cardiology, and the Canadian Society of Echocardiography. J Am Soc Echocardiogr 23(7):685-713. https://doi.org/10.1016/j.echo.2010.05.010 (quiz 786-688)

17. Rychik J, Tian ZY (1996) Quantitative assessment of myocardial tissue velocities in normal children with Doppler tissue imaging. Am J Cardiol 77(14):1254-1257

18. Colan SD, Borow KM, Neumann A (1984) Left ventricular endsystolic wall stress-velocity of fiber shortening relation: a loadindependent index of myocardial contractility. J Am Coll Cardiol 4(4):715-724

19. Lemmer Hunsinger CE, Engel ME, Stanfliet JC, Mayosi BM (2014) Reference intervals for the echocardiographic measurements of the right heart in children and adolescents: a systematic review. Cardiovasc Ultrasound 12:3. https://doi. org/10.1186/1476-7120-12-3

20. Cantinotti M, Lopez L (2013) Nomograms for blood flow and tissue Doppler velocities to evaluate diastolic function in children: a critical review. J Am Soc Echocardiogr 26(2):126-141. https:// doi.org/10.1016/j.echo.2012.11.017

21. Cantinotti M, Scalese M, Molinaro S, Murzi B, Passino C (2012) Limitations of current echocardiographic nomograms for left ventricular, valvular, and arterial dimensions in children: a critical review. J Am Soc Echocardiogr 25(2):142-152. https://doi. org/10.1016/j.echo.2011.10.016

22. Wang SS, Zhang YQ, Chen SB, Huang GY, Zhang HY, Zhang ZF, Wu LP, Hong WJ, Shen R, Liu YQ, Zhu JX (2017) Regression equations for calculation of $\mathrm{z}$ scores for echocardiographic measurements of right heart structures in healthy Han Chinese children. J Clin Ultrasound 45(5):293-303. https://doi.org/10.1002/ jcu.22436

23. Zhang YQ, Chen SB, Huang GY, Zhang HY, Huang MR, Wang SS, Wu LP, Hong WJ, Shen R, Liu YQ, Zhu JX, Lu ZH (2015) Coronary artery indexed diameter and $\mathrm{z}$ score regression equations in healthy Chinese Han children. J Clin Ultrasound 43(1):39-46. https://doi.org/10.1002/jcu.22176

24. Mentias A, Naji P, Gillinov AM, Rodriguez LL, Reed G, Mihaljevic T, Suri RM, Sabik JF, Svensson LG, Grimm RA, Griffin BP, Desai MY (2016) Strain echocardiography and functional capacity in asymptomatic primary mitral regurgitation with preserved ejection fraction. J Am Coll Cardiol 68(18):1974-1986. https:// doi.org/10.1016/j.jacc.2016.08.030

25. Rabkin SW, Cheng XJ, Thompson DJ (2016) Detailed analysis of the impact of age on the QT interval. J Geriatr Cardiol 13(9):740748. https://doi.org/10.11909/j.issn.1671-5411.2016.09.013

26. Zhou C, Chan HP, Hadjiiski LM, Chughtai A, Wei J, Kazerooni EA (2016) Coronary artery analysis: computer-assisted selection of best-quality segments in multiple-phase coronary CT angiography. Med Phys 43(10):5268. https://doi.org/10.1118/1.4961740

27. Pettersen MD, Du W, Skeens ME, Humes RA (2008) Regression equations for calculation of $z$ scores of cardiac structures in a large cohort of healthy infants, children, and adolescents: an echocardiographic study. J Am Soc Echocardiogr 21(8):922-934. https:// doi.org/10.1016/j.echo.2008.02.006

28. Cantinotti M, Kutty S, Franchi E, Paterni M, Scalese M, Iervasi G, Koestenberger M (2017) Pediatric echocardiographic nomograms: what has been done and what still needs to be done. Trends Cardiovasc Med 27(5):336-349. https://doi.org/10.1016/j. tcm.2017.01.006

29. Cantinotti M, Giordano R, Scalese M, Murzi B, Assanta N, Spadoni I, Maura C, Marco M, Molinaro S, Kutty S, Iervasi G (2017) Nomograms for two-dimensional echocardiography derived valvular and arterial dimensions in Caucasian children. J Cardiol 69(1):208-215. https://doi.org/10.1016/j.jjcc.2016.03.010 